\title{
Correspondence
}

\section{Cimetidine-antacid combination as premedication for elective Caesarean section}

To the Editor:

We read with great interest the article "Cimetidineantacid combination as premedication for elective Caesarean section" by Okasha et al. ${ }^{1}$

Since cimetidine prevents gastric secretion and has no effect on the material already present in the stomach the authors demonstrate that acid which is already present can effectively be neutralized by antacid. In conclusion they suggest that the combination of the neutralizing effect of antacids, with the marked reduction in gastric acidity and volume produced by cimetidine, provides a useful and safe adjunct for patients considered to be at risk from potential acid aspiration. The authors, however, do not stress the importance of appropriate spacing of the administration of the oral doses of the two medications. The purpose of this correspondence is to clarify the authors" conclusion because they may be misinterpreted to suggest that the two medications should be given together.

Steinberg et $a l .^{2}$ recently reported that antacids inhibit the absorption of cimetidine when given together and lower the cimetidine blood level. They suggest that an antacid be given at least 60 minutes before or after administration of cimetidine in the fasting state so that it will not interfere with the full suppressive effect of cimetidine on gastric acid. It is likely that the ingestion of antacids would not interfere with the effect of cimetidine given by the parenteral route.

Thomas J.K. Toung MD Department of Anesthesiology and Critical Care Medicine
John L. Cameron MD

Department of Surgery

Johns Hopkins Medical Institutions

Baltimore, Maryland 21205

REFERENCES

1 Okasha AS. Molaweh MM, Bali A. Cimetidineantacid combination as premedication for elective Caesarean section. Can Anaesth Soc J 1983: 30: 593-7.

2 Steinberg $W M$, Lewis $J H, K a t z D M$. Antacids inhibit absorption of cimetidine. N Engl J Med 1982; 307: $400-4$.

\section{Thoughts on the origins of a career in anaesthesia}

To the Editor:

Some time ago a few fellow-anaesthesiologists and I were reminiscing about our early experiences with anaesthesia and I recalled the following episode. I decided to share the memory with your readers.

It took place during my fourth undergraduate year (1943-1944). I had been selected to serve as an "extern" at the Misericordia Hospital in Winnipeg. One of the exciting tasks that fell to me was the provision of anaesthesia for emergency surgical procedures. Supervision was to be provided by the chief of anaesthesia, Dr. Jack Brenner. He usually did this from his home via the telephone

One evening I was called to the operating room to administer anaesthesia to a young boy who was to have an emergency appendectomy. Dr. Brenner would be at home should I run into trouble. As you can well imagine, this gave me little comfort. My only previous experience with anaesthesia - opendrop ether - had been with dogs in the physiology laboratory a few years earlier. Under my care, all the animals had died before any of the experiments could be completed.

Memories of these experiences raced through my mind as I slowly and unenthusiastically climbed the stairs to the operating room. Nor did my courage 
increase upon being told that the child had eaten a few hours ago. I knew enough to realize that this was a bad thing! The surgeon and his assistant assured me that they would monitor my performance closely and I was not to be concemed. "Don't worry," they said.

I placed several layers of gauze on the appropriate frame, held it over the patient's face and began to drop ether onto the gauze. It seemed only a matter of minutes before the surgeon decided that the patient was ready. The surgery was started and soon the surgeon's hand was inside the patient's abdomen.

He complimented me on the excellence of the abdominal wall relaxation, but with that, he paused, as if he had had some second thoughts. Perhaps it was the blue colour of the blood that had disturbed him. He quickly asked me to look at the pupils of the patient's eyes. I recall that they were dilated and fixed.

I looked around in panic. No one was breathing, not the nurses, not the surgeon and his assistant, not me, but the patient's nostrils seemed to be flaring feebly. At the surgeon's demand, I had removed the mask and was running some oxygen into the patient's mouth using an "ether hook." The patient began to breathe more vigorously and his colour had slowly improved.

Everyone had now relaxed, everyone that is, but I. The surgeon continued the procedure and although I had replaced the mask I was too terrified to drop any more ether. In a few moments the patient awoke and began to vomit. "Put him down," the surgeon shouted. Somehow I did put him down - down to the earlier stage of near respiratory arrest and deep cyanosis, "Let him up," came the surgeon's demand. Again the patient emerged to the vomiting level. "Put him down," came the cry from the other side of the screen.

In this manner, with terror and with shouts of "put him down" and "let him up" we finally reached the end of the procedure. The results of this event may be summarized as follows:

(1) The child made an uneventful recovery.

(2) The parents thanked me for my expertise.

(3) The surgeon had me banned from the operating room.

(4) I vowed that I would never have anything to do with anaesthesia again.

God thought otherwise however, for in January of 1951, I left "country practice" and commenced a residency in anaesthesia at the St. Boniface General
Hospital under Dr. Marjorie Bennett. And it was there that I spent the next 25 years in the practice of anaesthesia. I shall always be sincerely grateful to have had the opportunity, indeed the privilege, to participate in the academic growth of our specialty in Manitoba and in the political development of anaesthesia in Canada.

My wife and I moved to Phoenix in 1976. Neither the pleasant weather, the favourable economics, nor the easy working conditions of a practice confined to outpatient anaesthesia will ever diminish the memory and pleasure of a quarter century spent in the practice of anaesthesia in the province of Manitoba.

Max Minuck MD

684, North 3rd Place,

Phoenix, Arizona 85012

\section{Rebreathing and the Bain circuit}

To the Editor:

I read with interest the paper by Spoerel (Can Anaesth Soc J 1983; 30: 148-54), the subsequent comment by Imrie and the reply by Spoerel (Can Anaesth Soc J 1983; 30: 679-81).

The debate concerning the place of the Bain system for spontaneous respiration continues unabated, and appears to centre on the definition and significance of any rebreathing that may be observed. Because both are so differently interpreted by numerous investigators, it has become difficult to compare the results of the various papers. Those, like Spoerel, who feel that there is a place for the Bain for spontaneous respiration argue that the rebreathing that is evident at the lower fresh gas flows employed for Mapleson A systems, is not significant. Others argue that the obvious rebreathing presents a potential risk to every patient. '

I have already commented elsewhere on the diffculty in measuring the end point at which rebreathing can be said to begin to occur. ${ }^{2}$ However, rebreathing must be said to be significant when, after exchanging one breathing system for another under identical conditions, a rise in both inspired and end-expired $\mathrm{CO}_{2}$ tensians is observed. By employing this technique in anaesthetised adult patients, I directly compared the efficiency of the 